\title{
Keratosis Follicularis Spinulosa Decalvans
}

\author{
Report of Two Cases and Literature Review
}

Rhonda Rand, MD, Howard P. Baden, MD

\begin{abstract}
- We report herein two cases of keratosis follicularis spinulosa decalvans (KFSD) and review the literature on this condition. The entity is one of a group of related disorders that shows keratosis pilaris with inflammation followed by atrophy. The clinical features and course of KFSD are characteristic. During infancy, keratosis pilaris begins on the face and, by childhood, progresses to involve the trunk and extremities. Sometime during childhood or up to the early teenage years, a cicatricial alopecia of the scalp and eyebrows develops and is the hallmark of this disorder. Hyperkeratosis of the palms and soles is a frequently associated finding and is usually manifested during adolescence. Other features occurring with this syndrome include atopy, photophobia, and corneal abnormalities. Sex-linked inheritance has been proposed by several authors.
\end{abstract}

(Arch Dermatol 1983;119:22-26)

$\mathrm{T}$ here is a group of related disorders that is characterized by keratosis pilaris with inflammation followed by atrophy.,2 These diseases can be grouped under the more encompassing term "keratosis pilaris atrophicans" (KPA). Differences in location and the degree of inflammation and atrophy have been used to categorize these various disorders. Numerous and sometimes confusing terms for them are scattered throughout the literature. We propose that the following three clinical syndromes be considered as distinct but related disorders, all having in common the same pathogenetic mechanism of follicular hyperkeratosis, inflammation, and atrophy. The proposed disease titles represent a modification of a classification presented by Alchorne et $\mathrm{al}^{1}$ in 1973 and include KPA faciei (KPAF), atrophoderma vermiculatum (AV), and keratosis follicularis spinulosa decalvans (KFSD). Two cases of KFSD are presented.

\section{REPORT OF CASES}

CASE 1.-A 19-year-old man was seen in the Massachusetts General Hospital, Boston, dermatology clinic in August 1980 with progressive loss of the scalp hair. At 2 months of age, erythema of the forehead and cheeks developed, associated with horny papules and the absence

Accepted for publication Feb 16, 1982.

From the Department of Dermatology, Massachusetts General Hospital, Harvard Medical School, Boston.

Reprints not available. of hair on the lateral part of the eyebrows. Shortly after birth, keratotic papules became apparent on the posterior part of his scalp and persisted until he was 2 years old. He was diagnosed as having eczema and was treated with topical steroids without benefit. Keratotic papules developed on his trunk and extremities when he was approximately 5 years of age. For $1 \frac{1}{2}$ years before being seen in our clinic, the patient had noticed progressive loss of hair involving the parietal and occipital regions of the scalp. There was mild pruritus and tenderness, which caused interference with sports activities. The patient had been treated at different times with dicloxacillin sodium, ampicillin sodium, and erythromycin stearate without effect. The patient had a history of hay fever and photophobia. The first-degree relatives were examined, and pertinent histories were obtained. The maternal grandmother had hay fever, the mother had hay fever, ichthyosis vulgaris, and keratosis pilaris, and one of three female siblings had keratosis pilaris.

Physical examination showed a healthy-appearing young man. The skin was remarkable for horny keratotic follicular papules present on the extensor surfaces of the arms and the thighs, buttocks, and abdomen (Fig 1). Similar papules with an erythematous halo were present on the lateral part of the eyebrows and were associated with hair loss (Fig 2). Sparse, fine hair was present on the bearded region of the face and on the extremities. There was hyperkeratosis on the palms and soles. Erythema, scaling, follicular hyperkeratosis, pustules, and a scarring alopecia of the parietal and occipital regions were present on the scalp (Fig 3). The fingernails were thin, with longitudinal ridges and a few distal fractures. The teeth and mucous membranes were normal. Ophthalmologic examination disclosed punctate corneal defects. The 


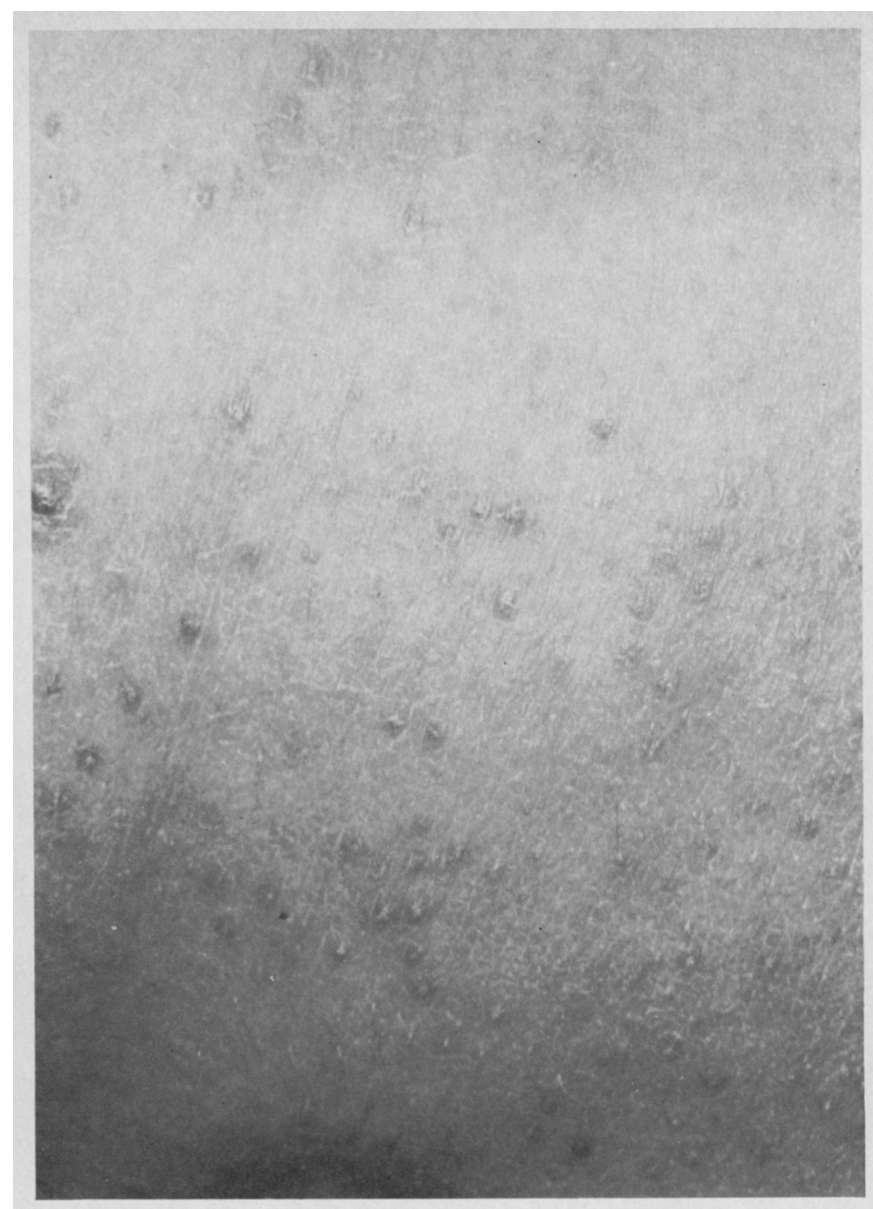

Fig 1. - Keratosis pilaris of abdomen (case 1 ).

Fig 2.- Thinning of eyebrows associated with follicular erythema and scarring (case 1).

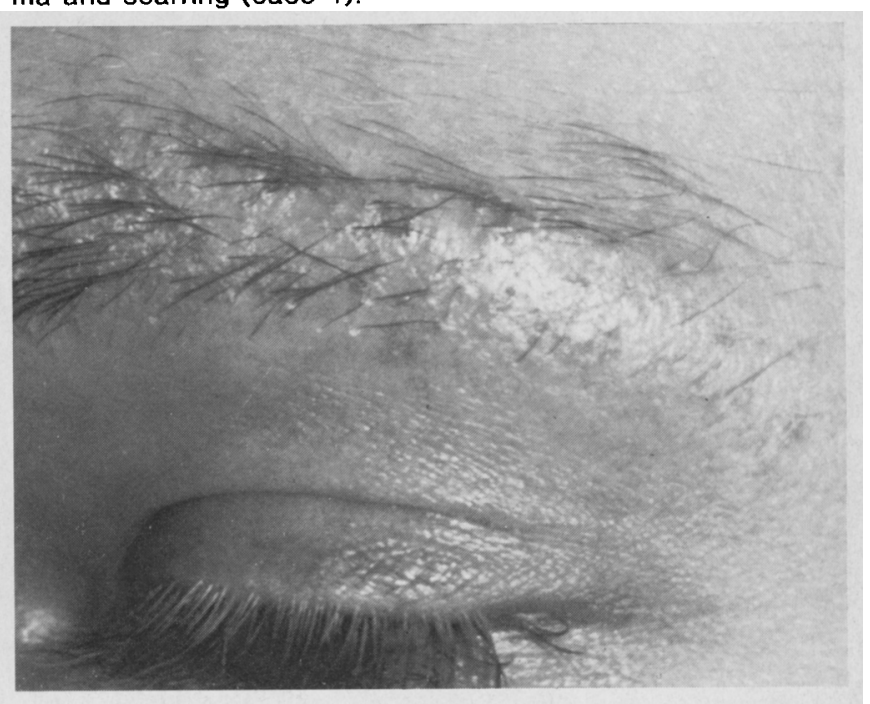

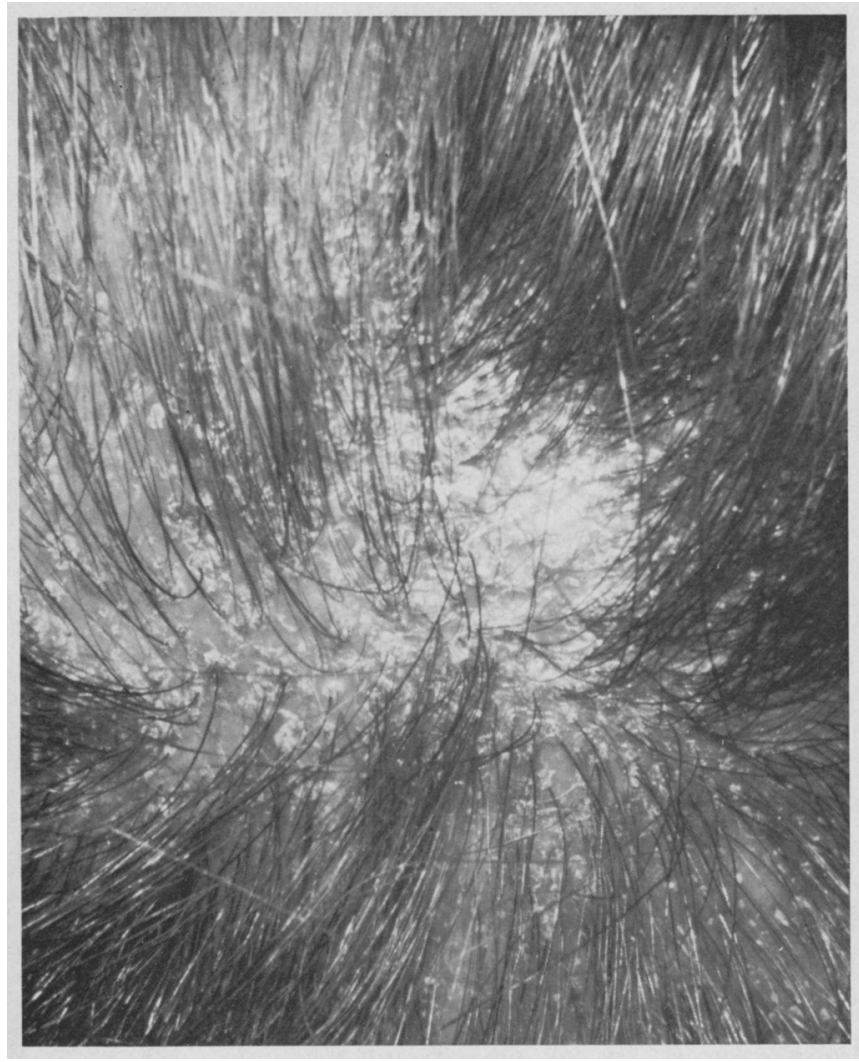

Arch Dermatol-Vol 119, Jan 1983
Fig 3. - Alopecia of scalp associated with follicular hyperkeratosis (case 1).

Fig 4. - Biopsy specimen from scalp showing scarred obliteration of hair follicles (case 1) (hematoxylin-eosin, $\times 37$ ).

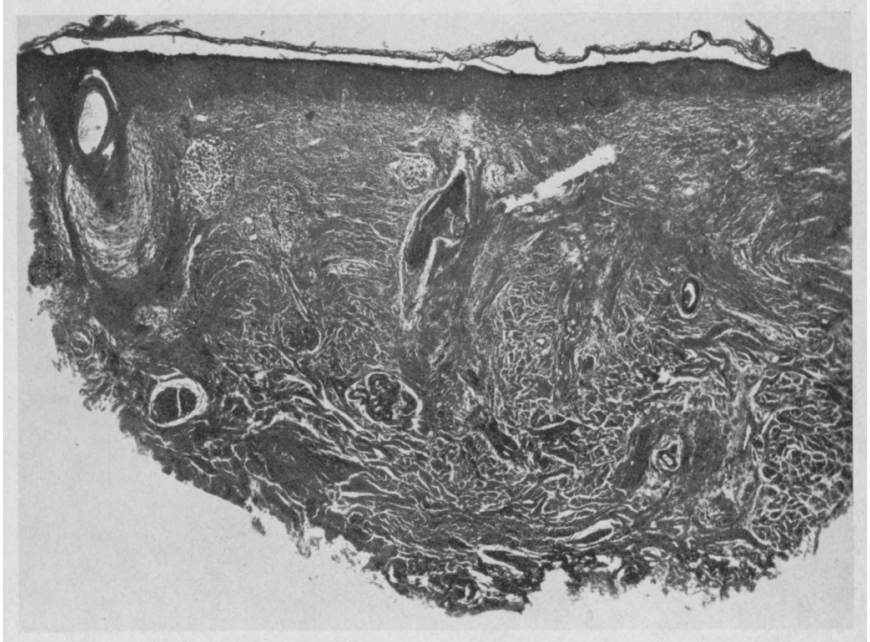

Keratosis-Rand \& Baden 


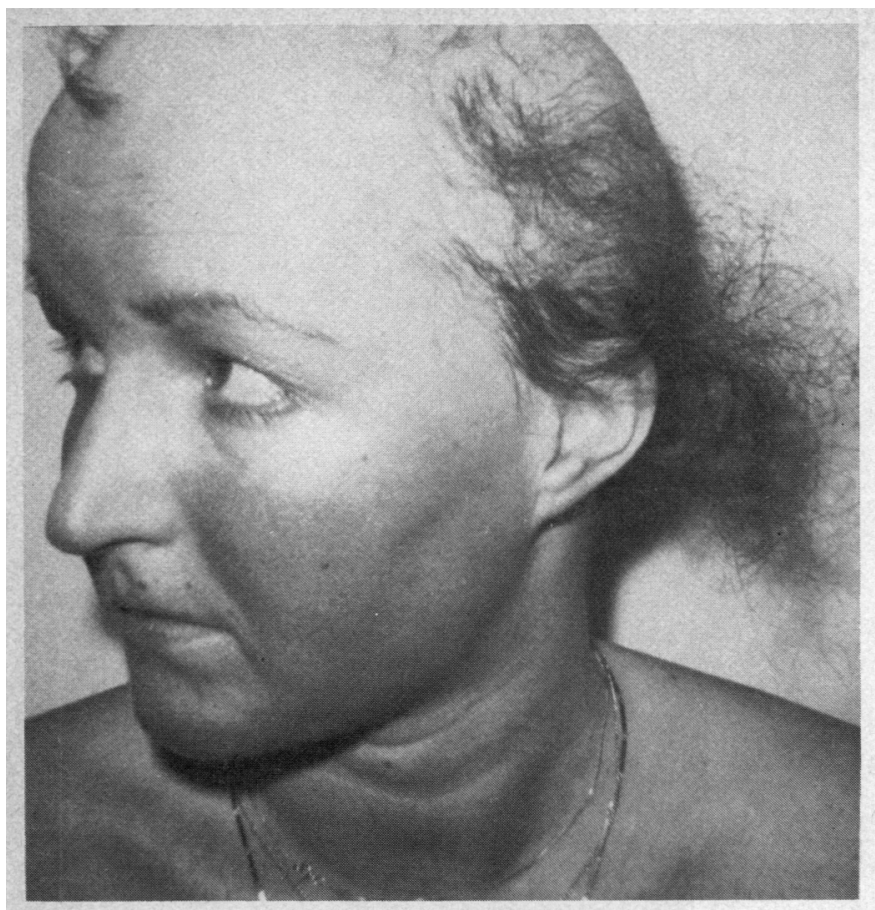

Fig 5.-Extensive alopecia of scalp (case 2).

results of the remainder of the physical examination were normal.

The following laboratory study values were either negative or normal: complete blood cell count and WBC differential count, ESR, and liver function. The vitamin A level was $0.47 \mu \mathrm{g} / \mathrm{mL}$ (normal, 0.15 to $0.60 \mu \mathrm{g} / \mathrm{mL}$ ). Coagulasepositive Staphylococcus aureus grew from a culture from the scalp. Cultures were negative for fungi.

A biopsy specimen from a scarred region of the parietal scalp showed a normal epidermis and horizontal lamellar fibrosis and vertical (follicular) scarring associated with a superficial and deep perivascular and periappendageal infiltrate of lymphocytes and plasma cells (Fig 4). A biopsy specimen from a follicular papule on the back showed a twisted hair. Perifollicular hemorrhage was observed and was probably a secondary effect caused by rubbing.

Vitamin A, in dosages up to 500,000 units/day, was given for two months to determine whether it would prevent follicular hyperkeratosis, but no treatment effect was seen. Because of the inflammatory changes noted, topical corticosteroid creams were applied, and injections of $3 \mathrm{mg} / \mathrm{mL}$ of triamcinolone acetonide were administered into multiple sites without benefit. At present, the patient is using a cream containing $12 \%$ lactic acid on the skin of the trunk and extremities; some softening of the keratotic papules has been noted.

CASE 2.-A 22-year-old woman was referred to the Massachusetts General Hospital for evaluation of extensive scalp alopecia. When she was 1 year old, she was diagnosed as having cradle cap. When she was an infant, erythematous, follicular papules of the cheeks, forehead, and eyebrows developed. Styes and loss of eyelashes were frequent complications because of eyelid involvement. Extensive keratosis pilaris and a progressive scalp alopecia developed during childhood. Topical corticosteroid therapy was tried, but it was of no help. It was necessary for her to wear a wig by the time she was 12 years old. When she was 14 years old, the diagnosis of pseudopelade was made. No biopsy specimen was obtained. The patient had mild hay fever and photophobia. Her father had hay fever and male pattern hair loss. Two of six siblings and a paternal uncle had psoriasis.

Physical examination disclosed a healthy-appearing young woman with extensive scarring alopecia of the scalp (Fig 5). There was widespread keratosis pilaris of the trunk and extremities and numerous, minute, follicular, erythematous papules on the cheeks, forehead, and eyebrows. The hair on the body was sparse, including the hair of the pubic area. There was no hyperkeratosis of the palms or soles. The nails and teeth were normal.

Biopsy specimens of follicular papules on the back and arm showed follicles filled with keratin and surrounded by mild chronic inflammation and fibrin.

\section{REVIEW OF THE LITERATURE}

The two patients with KFSD described in this article both were seen because of progressive scalp alopecia. Correct diagnoses had been delayed in both patients probably because of the scant literature published on this entity. Either the incidence of KFSD is extremely rare, or it is not being considered in the differential diagnosis of scarring alopecias. In an effort to increase awareness of the group of disorders comprising the more general entity of KPA, each disease will be defined and the literature on the disorder will be reviewed.

\section{KPAF}

Keratosis pilaris atrophicans faciei (ulerythema ophryogenes $^{3}$ or keratosis pilaris rubra atrophicans faciei $[\mathrm{KPRAF}]^{4}$ ) refers to an inflammatory process beginning in the eyebrows. Onset occurs a few months after birth in the lateral one third of the eyebrows with follicular papules surrounded by an erythematous halo. Eventually, there is loss of hair in the involved follicles. The process subsequently involves the cheeks and forehead. This entity is accompanied by keratosis pilaris of the extensor surface of the arms and occasionally of the thighs and buttocks. ${ }^{1.4}$ It is rare and has been observed in several family members, but the mode of inheritance has not been defined.

In 1878, Wilson ${ }^{5}$ was the first to report a syndrome characterized by erythematous follicular papules of the eyebrows, cheeks, back, and arms, sometimes associated with loss of the eyebrows, which he named "folliculitis rubra." However, this term was shortlived and the word "ulerythema" was introduced by Unna $^{6}$ in 1889 to describe a process leading to scar formation through the evolution of inflammatory cell infiltrates without pustulation. In 1889, Taenzer ${ }^{3}$ introduced the term "ulerythema ophryogenes" to describe a condition that began as follicular red papules of the eyebrows that eventually were followed by atrophy and alopecia. ${ }^{3}$ Brocq, ${ }^{7}$ in the same year, described a similar process involving the forehead, eyebrows, cheeks, jaws, and earlobes, which he termed "lichen pilaire" or "xerodermi pilaire symmetrique de la face." In 1948, Hecht ${ }^{4}$ described a family with KPRAF and reviewed the literature on this disorder. He postulated the existence of two separate disorders for what had previously been 
grouped together under the heading of KPAF. Both disorders start in early youth and display keratosis pilaris of the body in typical locations, but ulerythema ophryogenes initially involves the eyebrows and KPRAF initially involves the temples or cheeks. Subsequent authors have studied the association of ulerythema ophryogenes with other disease states. In 1964, Davenport ${ }^{8}$ reported a case of ulerythema ophryogenes associated with other ectodermal defects. A trial of vitamin A therapy had no effect. In 1969, Mertens ${ }^{9}$ observed 15 patients from five families with ulerythema ophryogenes and found most patients to have an atopic diathesis. Five cases of Noonan's syndrome associated with ulerythema ophryogenes were recently reported by Pierini and Pierini. $^{2}$

\section{AV}

Atrophoderma vermiculatum (acne vermoulanti, ${ }^{, 1}$ honeycomb atrophy, ${ }^{12}$ or folliculitis ulerythema reticulata $^{13}$ ) is a related syndrome. It is morphologically distinct, leaving pitlike depressions of the cheeks (reticulate atrophy). The preceding lesion is an erythematous follicular papule, and, therefore, some authors view this entity as the end stage of KPAF. The disease is rare and manifests itself when the patients are between the ages of 5 and 12 years.

In 1896, Unna ${ }^{14}$ introduced the term "ulerythema acneiforme" to describe follicular red papules of the cheeks that eventually progressed to reticulate atrophy. In 1900, Thieberge ${ }^{11}$ reported cases of honeycomb atrophy, which the discussant, Besnier, named "acne vermoulanti." In 1916, Pernet ${ }^{15}$ renamed this vermicular atrophy of the face "atrophodermia reticulata symmetrica faciei." In 1918, MacKee and Parounagian ${ }^{13}$ subsequently suggested the name "folliculitis ulerythematosa reticulata." In 1936, Winer ${ }^{16}$ used the term "atrophoderma reticulatum," whereas Savatard, ${ }^{12}$ in 1943 , named this syndrome "honeycomb atrophy." Two cases of folliculitis ulerythematosa combined with lichen spinulosus, epidermal cysts, and folliculitis decalvans were reported by Barber $^{17}$ in 1928. In 1950, Voge ${ }^{10}$ found this entity to have an autosomal dominant mode of inheritance. In 1959, Kooij and Venter ${ }^{18}$ reported a case of atrophodermia vermiculata with lesions on the neck and extremities associated with mongolism and congenital anomalies of Eisenmenger's complex and an interauricular septal defect.

\section{KFSD}

Keratosis follicularis spinulosa decalvans ${ }^{19}$ (keratosis pilaris decalvans ${ }^{2}$ or follicular ichthyosis ${ }^{20}$ ) refers to diffuse keratosis pilaris associated with a scarring alopecia of the scalp. Other features associated with this syndrome include atopy, hyperkeratosis of the palms and soles, photophobia, and corneal abnormalities. Sex-linked inheritance has been proposed by some authors. ${ }^{19,21}$

In 1909, MacLeod ${ }^{20}$ reported three cases of ichthyosis follicularis associated with baldness (probable KFSD) and reviewed the literature on the previously described syndromes with follicular inflammation and atrophy. The term "KFSD" was first used by Siemens $\mathrm{s}^{19}$ in 1926 in his description of a Bavarian family. The original description characterized the patients as having follicular papules of the face, trunk, and extremities. Scarring of the follicles was associated with partial loosening of the hair, eyelashes, and eyebrows. Typical eye symptoms included photophobia and inflammation of the cornea and conjunctivae. Involvement of eyelashes led to complications of blepharitis and punctate corneal defects. Palmar-plantar hyperkeratosis was a frequently associated finding. A sex-linked dominant type of inheritance was proposed, implying that the most severe manifestations were to be found in male patients. ${ }^{19}$ In 1933, Leven ${ }^{22}$ published the first case of a female patient who was severely affected. In 1940, Thelen $^{23}$ traced back for several generations the pedigree of the original family described by Siemens. In 1950, Jonkers ${ }^{24}$ also traced the pedigree of a family with this disease in the Netherlands. Holthuis ${ }^{2 s}$ described two patients who were related to Siemens' original proband who had keratitis that he thought to be secondary to keratotic spines and hardened secretions of the meibomian glands. Franceschetti et $a l^{26-28}$ reported several cases of this entity with characteristic findings of keratotic papules of the face, alopecia, corneal abnormalities, atopy, and photophobia. In 1971, Kuokkanen ${ }^{21}$ described KFSD in a family from northern Finland and reviewed the literature on this condition. Three successive generations were examined, and transmission by sex-linked inheritance was again proposed, but since there were so few cases reported, an autosomal dominant mode of inheritance cannot be excluded. Adler and Nyhan ${ }^{29}$ described a patient with KFSD who, in addition, had congenital glaucoma, lenticular cataract, mental retardation, arachnodactyly, and aminoaciduria.

In conclusion, we wish to reiterate our view that a group of related but distinct clinical disorders exists that is characterized by follicular hyperkeratosis and inflammation followed by atrophy. The three disorders can be grouped under the encompassing term "KPA." The classification is based on the location of the lesions and on the degree of atrophy that takes place, involving only the follicle in KPAF and KFSD but involving epidermis and dermis in $\mathrm{AV}$, resulting in pitlike depressions. The three features that distinguish these disorders from the many other cutaneous diseases that involve the follicle are onset in infancy, follicular hyperkeratosis, and endstage scarring.

No effective therapy is known. However, the presence of follicular hyperkeratosis implies that KPA may be a disorder of keratinization of the hair follicle. Retinoids have been shown to be beneficial in the treatment of many disorders of keratinization, ${ }^{30}$ and a therapeutic trial with a new synthetic retinoid is warranted.

This investigation was supported by grant AM-06838 from the National Institutes of Health. 
1. Alchorne AOA, Paes De Almeida JR, Fainzilber S: Queratosis follicularis. Med Cutan Iber Lat Am 1973;1:333-338.

2. Pierini DO, Pierini AM: Keratosis pilaris atrophicans faciei (ulerythema ophryogenes): A cutaneous marker in Noonan syndrome. $B r J$ Dermatol 1979;100:409-416.

3. Taenzer P: Ueber das ulerythema ophryogenes, eine noch nicht beschriebene hautkrankheit. Monatsschr Derm 1889;8:197208.

4. Hecht H: Keratosis pilaris rubra atrophicans faciei. Arch Dermatol 1948;58:41-46.

5. Wilson E: Lectures on Dermatology. London, J \& A Churchill, 1878, pp 217-220.

6. Unna PG: Ueber ulerythema sykosiforme. Monatsschr Derm 1889;9:134-140.

7. Brocq L: Lichen pilaire ou xerodermi pilaire symmetrique de la face. Ann Dermatol Venereol 1889;10:339-342.

8. Davenport DD: Ulerythema ophryogenes: Review and report of a case: Discussion of relationship to certain other skin disorders and association with internal abnormalities. Arch Dermatol 1964;89:74-80.

9. Mertens RLJ: Ulerythema ophryogenes and atopy. Arch Dermatol 1969;97:662-663.

10. Vogel L: Atrophoderma vermiculata. Dermatol Monatsschr 1950;122:669-674.

11. Thieberge G: Acne vermoulanti, in Besnier $\mathrm{E}$, Brocq $\mathrm{L}$, Jaquet L (eds): La Pratique Dermatologique. Paris, Masson, 1900, vol 1, p 207.

12. Savatard L: Honeycomb atrophy. $\mathrm{Br} \quad J$ Dermatol 1943:55:259-266.

13. MacKee GM, Parounagian MB: Folliculitis ulerythematosa reticulata. J Cutan Dis 1918;36:337.

14. Unna PG: Ulerythema acneiforme, in Histopathology of Diseases of the Skin. New York, Macmillan Publishing Co Inc, 1896, p 1084.

15. Pernet G: Atrophodermia reticulata symmetricia faciei. Med Press 1916;101:487.

16. Winer LH: Atrophoderma reticulatum. Arch Dermatol
$1936 ; 34: 980-988$.

17. Barber HW: Two cases of folliculitis ulerythematosa reticulata: Presented at the Royal Society of Medicine. Br J Dermatol 1928;40:24-26.

18. Kooij R, Venter J: Atrophodermia vermiculata with unusual localization and associated congenital anomalies. Dermatologica 1959;118:161-167.

19. Siemens HW: Keratosis follicularis spinulosa decalvans. Arch Dermatol Syphilol 1926;151:384-387.

20. MacLeod JMH: Three cases of ichthyosis follicularis associated with baldness. Br J Dermatol 1909;21:165-189.

21. Kuokkanen K: Keratosis follicularis spinulosa decalvans in a family from Northern Finland. Acta Derm Venereol 1971;51:146150 .

22. Leven SR: Kasuististischer beitrag zur keratoses follicularis spinulosa decalvans. Dermatol Monatsschr 1933;96:341-342.

23. Thelen: Keratosis follicularis spinulosa decalvans (Siemens). Zbl Haut Geschl Kr 1940;66:5-6.

24. Jonkers GH: Hyperkeratosis follicularis en cornea degeneratie. Ned Tijdschr Geneeskd 1950;94:1464-1472.

25. Holthuis P: Keratosis follicularis spinulosa decalvans. Ophthalmologica 1947;106:325.

26. Franceschetti A, Rossano R, Jadassohn W, et al: Keratosis follicularis spinulosa decalvans (Siemens). Dermatologica 1956; 112:512-514.

27. Franceschetti A, Jaccottet M, Jadassohn W: Manifestations corneennes dans la keratosis follicularis spinulosa decalvans (Siemens). Ophthalmologica 1957;133:259-263.

28. Franceschetti A, Jadassohn W, Paillard R: Keratosis follicularis spinulosa decalvans (Siemens). Dermatologica 1957;114:269270.

29. Adler RC, Nyhan WL: An oculocerebral syndrome with aminoaciduria and keratosis follicularis. $J$ Pediatr 1969;75:436442 .

30. Orfanos CE: Oral retinoids: Present status. $B r J$ Dermatol 1980;103:473-481. 